\title{
Conhecimento dos estudantes de enfermagem em relação às drogas psicotrópicas*
}

\author{
KNOWLEDGE OF NURSING STUDENTS ON PSYCHOTROPIC DRUGS \\ CONOCIMIENTO DE LOS ESTUDIANTES DE ENFERMERÍA EN RELACIÓN \\ A LAS DROGAS PSICOTRÓPICAS
}

Fernanda Vieira de Campos', Cássia Baldini Soares ${ }^{2}$

\begin{abstract}
RESUMO
O objetivo deste estudo é caracterizar a situação de aprendizado dos estudantes de enfermagem sobre drogas psicotrópicas. Foram entrevistados estudantes de uma escola pública e uma privada. A análise dos dados foi temática. Os resultados não apontam diferenças substanciais entre as escolas, mostrando: aprendizado centrado nos psicofármacos; influência da mídia e utilização do senso-comum na epidemiologia, motivações e problemas advindos do uso de drogas, reprodução de mitos e preconceitos sobre usuários; desconsideração dos conflitos sociais que permeiam as drogas. É necessário aperfeiçoar o ensino desses conteúdos para que os estudantes tenham uma base de conhecimento adequada nos espaços de atuação.
\end{abstract}

\section{PALAVRAS-CHAVE}

Educação em enfermagem. Drogas ilícitas.

Preconceito.

\author{
ABSTRACT \\ The objective of this study is to \\ characterize the learning \\ situation of nursing students \\ with regard to psychotropic \\ drugs. Students from a public \\ and a private school were \\ interviewed. Data analysis \\ was thematic. The results do \\ not suggest substantial \\ differences between the \\ schools regarding: learning \\ centered on psychophar- \\ macology; influence of media \\ and use of common sense in \\ the epidemiology; motivations \\ and problems related to drug \\ use; myth repetition and \\ prejudice of users; disrespect \\ of the social conflicts that \\ involve drug problems. \\ It is necessary to improve \\ education on this topic so \\ that students will have \\ adequate knowledge to act \\ as professionals.
}

\section{KEYWORDS}

Nursing education.

Street drugs.

Prejudice.

\section{RESUMEN}

El objetivo de este estudio fue caracterizar el estado de conocimiento sobre drogas psicotrópicas en estudiantes de enfermería. Se entrevistaron estudiantes de una escuela pública y de una privada. El análisis de los datos fue temático. Los resultados no muestran diferencias substanciales entre las escuelas. Se evidencia conocimiento centrado en los psicofármacos; influencia de los medios de comunicación y la utilización del sentido común en la epidemiología; motivaciones y problemas resultantes del uso de drogas; reproducción de mitos y prejuicios sobre los usuarios; desconsideración de los conflictos sociales que permean las drogas. Es necesario mejorar la educación de esos contenidos para que los estudiantes tengan una base de conocimiento adecuada en los espacios de actuación.

\section{PALABRAS CLAVE}

Educación en enfermería. Drogas ilícitas.

Prejuicio.

\author{
Apresentado no $10^{\circ}$ \\ Simpósio Internacional \\ de Iniciação Científica \\ da USP, 2002. \\ 1 Estudante de \\ Enfermagem e \\ bolsista de Iniciação \\ Científica PIBIC- \\ $\mathrm{CNPq}$.Departamento \\ de Enfermagem em \\ Saúde Coletiva da \\ Escola de Enferma- \\ gem da USP (EEUSP). \\ fernandavcampos \\ @hotmail.com \\ 2 Enfermeira. Mestre \\ em Saúde Pública. \\ Doutora em Educação. \\ Professora Doutora \\ do Departamento de \\ Enfermagem em \\ Saúde Coletiva da \\ EEUSP. \\ cassiaso@usp.br
}


Fernanda Vieira de Campos Cássia Baldini Soares (a) Um programa iniciado em 1997 na Faculdade de Medicina, Campus de Botucatu. <http://www.viverbem. fmb.unesp.br/> (b) O Programa de Prevenção e

Tratamento do Uso de Drogas na USP iniciou suas atividades em 1995 com uma pesquisa epidemiológica entre os estudantes de graduação da USP capital. <http:// www.usp.br/medicina/ grea/produsp/>

(c) O projeto, originário da Escola de Enfermagem da USP, é dirigido à comunidade universitária, principalmente aos estudantes da USP e objetiva a prevenção de prejuízos relacionados ao uso de drogas.

(d) A exemplo do "III Workshop Nacional sobre a Inserção do Conteúdo de Álcool e Drogas nos Currículos de Graduação em Enfermagem", promovido pela Universidade Federal Paulista de São Paulo, São Paulo, 4 de dezembro de 1999 , como parte do Projeto de Capacitação de Docentes de Enfermagem em Redução da Demanda de Drogas da OEA.

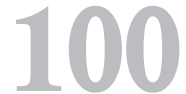

Rev Esc Enferm USP 2004; 38(1): 99-108.

\section{INTRODUÇÃO}

O objeto deste estudo diz respeito ao aprendizado dos conteúdos referentes às drogas psicotrópicas nos cursos de graduação em enfermagem. Parte-se do pressuposto de que o ensino desses conteúdos nas escolas parece estar se restringindo, na maioria das vezes, ao desenvolvimento de temas diretamente relacionados ao tratamento de problemas mentais, ou seja, à utilização de psicofármacos para sofrimentos psíquicos diagnosticados.

Sabe-se, no entanto, que os diversos usos de drogas - lícitas e ilícitas - abrangem uma gama ampla de outras dimensões, relacionando-se com prejuízos sociais e de saúde que revelam na sua essência a magnitude e a complexidade do problema, a ausência de políticas sociais públicas de qualidade e a precariedade das iniciativas que se pretendem situar no campo da prevenção ${ }^{(1-3)}$.

De fato, o dimensionamento epidemiológico do uso de drogas reporta que, apesar de não se ter história de um uso em níveis epidêmicos ${ }^{(4)}$, especialmente quando comparado a outros países ${ }^{(5)}$, a extensão e a gravidade do uso de drogas lícitas, muito mais do que ilícitas, tem sido motivo de preocupação por parte de diversos estudiosos que se detêm especialmente diante da magnitude do uso e dos prejuízos relativos ao uso de álcool e de tabaco ${ }^{(6-8)}$.

A extensão do problema no meio universitário parece adquirir características ainda diferenciadas $^{(9-11)}$. Pesquisas recentes revelam que, na Universidade de São Paulo, a droga mais utilizada pelos estudantes universitários foi, na verdade, lícita $(90,1 \%$ dos estudantes já experimentaram álcool na vida). No que se refere ao uso de drogas ilícitas achou-se que: $20 \%$ dos estudantes fizeram uso de maconha nos últimos 12 meses; o uso na vida de cocaína foi relatado por $10,2 \%$ dos estudantes do período noturno, da área de ciências humanas, destacando-se em relação aos demais ${ }^{(9,10)}$. Particularmente, entre estudantes de enfermagem da Escola de Enfermagem de Ribeirão Preto, o álcool também foi a substância psicotrópica mais citada pelos estudantes $(78,2 \%)$, ficando o tabaco em segundo lugar $(28,9 \%)$. Entre as drogas consideradas ilícitas, a maconha foi a mais freqüentemente citada, atingindo 9,26\% dos estudantes ${ }^{(12)}$
A prevenção, historicamente no Brasil, tem se caracterizado pela omissão das autoridades na viabilização de práticas adequadas à complexidade que o processo exige ${ }^{(13)}$. As práticas têm seguido a política de "guerra às drogas", limitando-se a ações de caráter repressivo e favorecendo intervenções casuístas e inadequadas baseadas em estratégias repressivas condenadas por avaliações de âmbito nacional e internacional (1-3). Trata-se da utilização de palestras esporádicas, em geral, ministradas por "especialistas" que reduzem e simplificam o problema, utilizando-se de discursos amedrontadores e que exageram um lado do problema, por vezes, falseando comprovações cientificamente balizadas. Somadas ao encaminhamento alarmista da mídia e dos discursos oficiais, tais práticas fomentam o tratamento preconceituoso e estigmatizante socialmente dispensado ao usuário $^{(14)}$, inclusive nos serviços de saúde submetendo-o, muitas vezes, à marginalização e à exclusão social ${ }^{(3,15)}$.

A prevenção no meio universitário também, a exemplo de outros setores, vem sendo considerada falha historicamente ${ }^{(16)}$. Observa-se, no entanto, iniciativas recentes nesse sentido, como é o caso do Projeto Viver Bem $^{(a)}$ da Unesp, do PRODUSP(b) e do projeto "Formando multiplicadores universitários em prevenção e redução de danos associados ao uso de drogas “(c) da USP $^{(17)}$

A participação da enfermagem no projeto nacional e mundial da prevenção ao uso de drogas tem sido gradualmente ampliada, notavelmente com o advento dos encaminhamentos recentes coordenados por agências internacionais. Os conteúdos a serem explorados, para dar conta da complexidade social que o processo do uso de drogas envolve, têm sido motivo de preocupação dos docentes de escolas de enfermagem, constituindo-se em tema central de uma série de seminários que reuniram aqueles que têm experiência com o tema ${ }^{(\mathrm{d})}$. Alguns levantamentos evidenciaram a precariedade dos conhecimentos sobre drogas adquiridos pelos alunos de enfermagem ${ }^{(18)}$ e a vulnerabilidade do ensino sobre dependência química nos cursos de graduação em enfermagem no Brasil no ano de $1998^{(19)}$.

Nesse sentido, um diagnóstico que aprofunde e particularize as deficiências e 
álcool e drogas no ensino de enfermagem constitui-se em uma das tarefas a serem cumpridas por aqueles que estão envolvidos com o encaminhamento de políticas sociais públicas de prevenção, particularmente, no que concerne ao ensino de graduação em enfermagem.

O objetivo deste trabalho é caracterizar a situação de aprendizado dos conteúdos sobre drogas psicotrópicas dos estudantes de enfermagem durante a graduação.

\section{CONSIDERAÇÕES TEÓRICAS: PARA ALÉM DA DROGA}

A teoria na qual este projeto se baseia concebe que um processo complexo deve ser considerado na análise do consumo de drogas. Assim, é bastante disseminada, entre especialistas de diferentes áreas, a abordagem teórica que remete a compreensão da relação dos indivíduos com as drogas à consideração de uma rede intrincada e complexa de dimensões ligadas às características singulares dos indivíduos, às drogas utilizadas - com suas propriedades farmacológicas - e aos diversos contextos sociais determinados pela dinâmica e estrutura do modo de produção vigente ${ }^{(3)}$.

A abordagem preventiva que metodologicamente encaminha essa base teórica é conhecida como redução de danos. Trata-se de uma abordagem que se contrapõe à da guerra às drogas, que se desenvolveu majoritariamente nos Estados Unidos, e propõe ações relacionadas apenas ao pólo das drogas, desconsiderando os aspectos ligados aos indivíduos e aos contextos sociais que os envolvem. Além disso, entre outras coisas, é uma proposta que vê os usuários de drogas como marginais frente à sociedade, apenas aceitáveis desde que livres das drogas ${ }^{(20-21)}$.

Ao contrário, a redução de danos pressupõe que o uso de drogas é uma realidade que tem se verificado ao longo da história cujas variáveis dependem de complexa rede formada pela relação dos indivíduos com as drogas e, portanto, não parte de uma visão idealista de que possa existir uma sociedade livre de drogas e de que combater a droga seja a ação suficiente para eliminar o consumo. ${ }^{(20-23)}$

Dessa forma, acredita-se que as medidas de prevenção e controle devem enfocar não somente a droga em si, mas também os aspectos subjetivos que mediam essa relação e aqueles relacionados às agências e espaços de socialização - a família, a escola, o trabalho e a mídia - através das quais as crianças e jovens apreendem a cultura e sofrem as determinações históricas da estrutura e dinâmica da sociedade.

\section{PROCEDIMENTOS METODOLÓGICOS}

Este estudo, de natureza qualitativa, tem um caráter exploratório. A população de estudo foi constituída por estudantes de graduação em enfermagem do último ano de duas escolas, sendo uma pública (Escola de Enfermagem da USP) e uma privada (Faculdade São Camilo), com estruturas curriculares já densamente consolidadas. Os critérios para participação na pesquisa foram: voluntariedade; matrículas regulares; não existência de defasagem escolar e uma média ponderada entre 6 e 8 . Assim, participaram da pesquisa 15 alunos da Faculdade São Camilo e 13 da EEUSP. A coleta de dados foi realizada no segundo semestre de 2001, após obtenção do consentimento das diretorias e a aprovação do Comitê de Ética em Pesquisa da Escola de Enfermagem da USP e da Faculdade São Camilo. Todos os participantes souberam com antecedência dos objetivos da pesquisa e assinaram um Termo de Consentimento. A coleta dos dados foi realizada através de entrevista estruturada com as seguintes questões norteadoras: $\mathrm{O}$ que são drogas psicotrópicas? Como são classificadas? (Quais os efeitos sobre o Sistema Nervoso Central?) Quais as drogas mais utilizadas? O que é síndrome de abstinência? O que é overdose? O que é tolerância? Quem usa drogas no Brasil contemporâneo? E no mundo? Por que as pessoas usam drogas? (Quais são as motivações para o uso de drogas?) Quais são os critérios que definem se uma droga é lícita ou ilícita? Quais são os problemas provenientes do uso de drogas? O que você acha que a sociedade deve fazer a respeito do uso de drogas? O que é preciso fazer para prevenir? Em que disciplina(s) aprendeu sobre drogas na graduação? Em que outros lugares/situações você aprendeu sobre drogas? Você se sente preparado para uma atuação profissional relacionada ao campo das drogas? Na área de prevenção? Ou tratamento?
Conhecimento dos estudantes de enfermagem em relação às drogas psicotrópicas 
Fernanda Vieira de Campos Cássia Baldini Soares
O teste piloto foi realizado com estudantes da Escola de Enfermagem da UNIFESP, consistindo de duas entrevistas.

A análise dos dados foi realizada mediante os critérios de análise temática de Bardin $^{(24)}$, que pressupõe que o tema é

a unidade de significação que se liberta naturalmente de um texto analisado segundo certos critérios relativos à teoria que serve de guia à leitura.

Para tanto, percorreu-se o processo de categorização e

de codificação, isto é, uma classificação dos dados de acordo com as categorias teóricas iniciais ou segundo conceitos emergentes,

levando em consideração que novas categorias poderiam surgir do material empírico coletado $^{(25)}$. Esse processo foi seguido de uma quantificação que ajudou a perceber a freqüência com que as respostas foram obtidas, facilitando a organização do material. Os depoimentos mais significativos de estudantes de escola privada (Esc Priv) e estudantes de escola pública (Esc Pub) foram editados e transcritos para conferir clareza à descrição dos resultados.

\section{RESULTADOS}

Os resultados são apresentados de acordo com os temas e subtemas encontrados no material coletado, formulados a partir dos referenciais teóricos deste estudo.

\section{Tema 1: Conhecimento científico sobre drogas}

Os entrevistados das duas escolas utilizaram um conceito científico sobre drogas psicotrópicas, sendo as respostas semelhantes ao conceito de Masur e Carlini ${ }^{(6)}$ :

Droga psicotrópica é aquela que age no cérebro, modificando o seu funcionamento, trazendo como consequência alterações do comportamento e do psiquismo.

Foi também expressiva, entre os estudantes da escola privada, a definição de droga psicotrópica como causadora de dependência, um conceito que enfoca o âmbito das consequências que podem advir do uso de drogas. No entanto, é possível perceber a presença significativa de um conceito reduzido à relação imediata entre droga psicotrópica e psicofármaco, expressa na definição de droga psicotrópica como medicação controlada ou como instrumento no tratamento da doença mental.

Os entrevistados demonstraram construir a classificação das drogas segundo seu efeito no sistema nervoso central, baseados em noções de senso-comum: desconhecem inteiramente ou classificam erroneamente, segundo outros critérios. Para analisar este subtema tomou-se como referência o conceito científico expresso por Masur e Carlini( $^{(6)}$, que classifica as drogas em três grupos: estimulantes, depressores e perturbadores do Sistema Nervoso Central.

Houve uma única resposta, na escola privada, que mais se aproximou de uma classificação científica, porém incompleta, sem que fossem mencionadas as drogas perturbadoras. Ao contrário, embora incompletas, mais alunos da escola pública apresentaram respostas aproximadas de uma classificação científica.

Quando perguntados sobre quais são as drogas mais utilizadas, a grande maioria dos entrevistados pediu esclarecimento ao entrevistador para saber se se tratavam de "drogas em geral" ou "psicofármacos". Tal dúvida evidenciou um certo viés dos estudantes, que pode ser atribuído ao tipo de aprendizado a que os estudantes têm tido acesso. Mesmo após a confirmação do entrevistador de que se tratavam de "Drogas em geral", a maioria insistiu em citar os psicofármacos e até mesmo alguns medicamentos como sendo as drogas mais utilizadas. O psicofármaco mais citado na escola privada foi o "Dormonid" (ansiolítico), e na escola pública foram citadas as classes dos ansiolíticos e antidepressivos. Em seguida, vieram a maconha, a cocaína e as anfetaminas na escola privada, e maconha, álcool e cigarro respectivamente na escola pública. Não houve citação de álcool e cigarro na escola privada, ficando as drogas lícitas de fora do campo das drogas mais utilizadas. Nesse sentido, parece ser precário o conhecimento dos estudantes a respeito da epidemiologia das drogas psicotrópicas, seguindo um parâmetro de senso comum, uma vez que, de acordo com os levantamentos epidemiológicos de que se dispõe - tomados como parâmetro científico neste estudo - as drogas lícitas são as responsáveis pela maior prevalência de uso na vida ${ }^{(7-8)}$. 
Para complementar o conhecimento epidemiológico sobre o uso de drogas psicotrópicas, apresenta-se os resultados relativos à opinião dos entrevistados sobre os perfis dos usuários no Brasil contemporâneo. Os estudantes opinaram majoritariamente ser o uso generalizado, sem que fossem apontadas distinções demográficas ou sociais, mostrando desconhecer as diferentes prevalências entre os usuários e usando mais uma vez o senso-comum.

Logo em segundo plano, as duas escolas citaram os jovens como compondo a maioria dos usuários. Novamente, sem se basear em estudos epidemiológicos, os estudantes parecem se valer de informações não científicas, uma vez que um levantamento domiciliar recente, de âmbito nacional ${ }^{(8)}$, aponta as maiores prevalências entre adultos e adultos jovens a depender da droga utilizada.

$\mathrm{Na}$ escola pública foram ainda relacionados aqueles com problemas de saúde como os maiores usuários de psicotrópicos e houve uma citação de grupo de risco.

As respostas sugerem não haver diferenças epidemiológicas entre usuários no Brasil ou no mundo, o que se trata de uma nova generalização imprecisa, pois os levantamentos científicos referem a existência de diferenças importantes entre os países, especialmente, entre aqueles de capitalismo central e periférico ${ }^{(8)}$.

Alguns casos isolados mencionaram que o uso é maior nos países produtores e consumidores - sem explicitar quais sãoou países que estão em situação de guerra. Novamente, tratam-se de afirmações sem fundamento no conhecimento produzido, provavelmente baseadas em vagas noções que circulam socialmente.

Os discursos parecem traduzir influências de informações vagas e incertas, veiculadas pela mídia, em geral, que tendenciosamente proscreve as drogas ilícitas enquanto "anunciam-se maravilhas" sobre as lícitas, atribuindo ao jovem o grande consumo ${ }^{(26)} \mathrm{e}$ estimulando a produção e reprodução de mitos e preconceitos sobre as drogas.

Síndrome de abstinência ${ }^{(27)}$ é um conjunto de sinais e sintomas decorrentes da falta de drogas em usuários dependentes. Caracteriza- se por sensações de mal-estar e diferentes graus de sofrimento mental e físico, particulares para cada tipo de droga. De maneira geral, os estudantes mostraram-se sem domínio pleno do conceito científico de síndrome de abstinência.

O conceito de overdose ${ }^{(27)}$, está relacionado a uma

superdosagem, ou dose excessiva de uma substância que debilita o organismo, provocando falência de órgãos vitais, como coração e pulmões.

Os entrevistados responderam à essa questão aproximando-se do conceito científico. Contudo, o número considerável de respostas incompletas, sem explicitação dos mecanis-mos causados pela overdose no organismo, mostram desconhe-cimento do processo pelo qual a overdose pode, eventualmente, levar a morte.

Tolerância ${ }^{(27)}$ é a capacidade de se resistir à ação de uma droga, necessitando aumentar a dose para obter o mesmo efeito anteriormente encontrado. A grande maioria das respostas não foi compatível com esse conceito científico, reproduzindo-se conceitos de senso-comum.

Respostas semelhantes para tolerância e síndrome de abstinência foram encontradas em um levantamento realizado em 25 escolas de enfermagem de todo país, em $1998^{(19)}$.

\section{Tema 2: Mitos e preconceitos a respeito de drogas}

A maioria dos entrevistados, quando questionados a respeito dos motivos para o uso de drogas, recorreu aos estereótipos que socialmente têm sido atribuídos aos usuários, referindo-se restritamente às motivações de caráter emocional: fuga de problemas, autoafirmação, influência dos amigos, curiosidade, entre outras.

O uso terapêutico foi consideravelmente lembrado pelos respondentes da escola privada, lembrando-se mais uma vez da função dos psicofármacos.

Embora minoritário, o uso de drogas por prazer foi também incluído pela escola pública, mostrando alguma abertura para fugir dos padrões moralmente aceitos e disseminados a respeito das motivações.
Conhecimento dos estudantes de enfermagem em relação às drogas psicotrópicas 
Fernanda Vieira de Campos Cássia Baldini Soares
(...) Porque elas gostam, porque a sensação de usar maconha, de beber uma cerveja, de fumar um cigarro, é indescritível. (Esc. Pub.)

Observa-se aqui, como em outros trabalhos, a existência de um estereótipo de usuário, que é traduzido em uma pessoa vulnerável, incapaz de solucionar seus problemas $^{(3,28-29)}$, sem que o consumo da droga seja processualizado como uma mercadoria de uma empresa que obtém o segundo maior contigente de lucro, só perdendo para o comércio de armas, igualmente destrutivo ${ }^{(30)}$.

Entre os entrevistados, a maioria entendeu que a legalidade de uma droga está relacionada à capacidade de causar problemas de saúde, inclusive a dependência, e aos efeitos terapêuticos da droga. Muitos não souberam identificar os critérios que estabelecem a legalidade de uma droga. Na mesma proporção, os alunos da escola pública limitaram-se a atribuir ao governo o poder de liberar as drogas, sem, no entanto, estabelecer quais são os critérios utilizados. Na escola privada, apenas uma vez, o critério de legalidade foi relacionado ao poder econômico, de geração de impostos.

Assim, a regra social sobre a legalidade de uma droga parece ser entendida como fruto, de um lado, das preocupações sociais com a saúde - modelo da saúde pública, que vê o uso de drogas como doença-e, de outro, dos interesses econômicosmodelo jurídico-moral, que através do Estado, executa as leis de acordo com os interesses econômicos hegemônicos, tratando o uso como crime ${ }^{(3)}$.

Tanto os alunos da escola privada como os da pública enumeraram uma série de problemas como provenientes do uso de drogas: os problemas orgânicos prevaleceram na escola pública ao passo que os problemas sociais preocuparam mais os estudantes da escola privada.

(...) físicos... (...) dizem que maconha dá câncer de pulmão, mata os seus neurônios, até estimula sua capacidade plástica. (...) Do seu cérebro, é lógico... (Esc. Pub.)
(...) a pessoa drogada vai querer roubar, vai querer achar dinheiro de qualquer jeito pra comprar alguma pedra de crack que ele tá viciado, ou mesmo comprar o pó que ele tá viciado a fazer isso, que ele começa em casa, ele rouba a mãe e o pai, depois ele sai por aí... roubando qualquer um (...) (Esc. Priv.)

Diferentemente da tendência majoritária, alguns estudantes da escola pública se preocuparam com os problemas psicológicos como a perda da capacidade de julgamento.

Assim, os estudantes enumeraram fluentemente uma série de problemas que o uso de drogas pode acarretar. O caráter inevitável desses problemas foi se evidenciando nas falas pela monossemia discursiva, não aparecendo relativizações, que poderiam se verificar, por exemplo, na menção à possibilidade de existirem diferentes padrões de uso ou mesmo na admissão da existência de uso controlado de alguma substância psicoativa. Os estudantes parecem haver absorvido os discursos assertivos sobre drogas, socialmente difundidos: pelos livros didáticos ${ }^{(31)}$; pelos textos oficiais e jornalísticos ${ }^{(28)}$; pelas revistas direcionadas a adolescentes ${ }^{(29)}$.

\section{Tema 3: Intervenção social: guerra às drogas $x$ redução de danos}

De maneira geral, para intervir sobre o problema das drogas, a escola privada deu maior ênfase às propostas sociais que preconizam menos discriminação ao usuário, aproximando-se da abordagem da Redução de Danos. Já a escola pública tendeu a formular propostas de aumento do controle social sobre o uso de drogas, aproximandose das propostas que têm historicamente alimentado a abordagem da Guerra às Drogas.

Assim, as propostas ligadas à abordagem da guerra às drogas apareceram das seguintes formas:

a) devido ao fatalismo, à falta de propostas, no apelo às soluções "de fé".

(...) eu não vejo uma solução (...) Acho que só Deus se tivesse aqui, teria uma solução, mas acho que a sociedade não consegue.(Esc. Priv.)

b) na reprodução da intolerância ao usuário, através da punição e maior controle e rigidez. 
(..) se você sabe de alguém que usa (...)qualquer droga (...) deveria ser denunciado (...) (Esc.Pub.)

c) na permanência de campanhas.

d) no reforço ao controle dos pais sobre os filhos.

e) no alerta sobre os males que a droga traz, expondo apenas o lado negativo do uso.

Sociedade? Deve... esclarecer, permitir um esclarecimento pras pessoas deixem de usar, esclarecendo que faz mal... (Esc. Priv.)

Caminhando na direção oposta, as propostas mais próximas à abordagem da redução de danos preconizaram:

a) refletir sobre saídas que vão da descriminalização do usuário até a liberação do uso.

(...) eu acho que informar tá mais do que informado (...) a liberação é uma alternativa porque, eu acho que quem não é viciado, e não é porque liberou que vai ser, e quem já é, não tem o que fazer porque é muito fácil adquirir isso no nosso país (...)Todo mundo sabe onde vende, todo mundo sabe onde compra (Esc. Pub.)

b) a possibilidade de aceitar um julgamento individual, baseado nas escolhas de cada um.

(...) eu acho que, você tem que coibir, mas também se a pessoa for usar dentro da casa dela, você não tem que tirar a liberdade dela, entendeu? Eu acho que você tem que tirar (...) esse peso de cima das drogas, que faz elas ficarem mais atraentes, e coloca as pessoas num submundo que ela não precisa. É escolha, esclareça... Se ele escolher, tá escolhido (Esc. Pub.)

c) a educação preventiva através de ações de orientação dos pais, dos professores, dos trabalhadores da saúde.

(...)pai e mãe eu acho que é a maior conscientização que a gente tem, que é a criança desde quando ela é pequena (...). E a segunda prevenção é a própria escola, né, o programa (...) de educação pra esse tipo, né, porque se fala muito em educação sexual mesmo na escola, mas se fala pouco em educação sobre drogas (Esc. Priv.) d) a importância da prevenção através de atividades educacionais e de orientação que promovam a contra-ideologia, permitindo um espaço educativo crítico em relação à abordagem tendenciosa das propagandas atuais.

\section{(...) eu não sei se aqueles comerciais que passam na televisão induz mais ou previ- ne alguma coisa (...) (Esc. Priv.)}

e) o desenvolvimento de propostas congruentes com os modelos de "educação afetiva" e de "oferecimento de alternativas" para a prevenção ao uso de drogas.
(...) oferecer educação, oferecer alimen- tação, oferecer saúde, boas condições de saúde, moradia, pra tá tentando dimi- nuir assim, a procura (...) a partir do mo- mento que você oferece educação, comi- da, um bom salário, emprego, lazer (...)você não vai ter um motivo especial pra tá procurando (...) (Esc. Priv.)

f) recordou-se também a necessidade de esclarecer sobre a possibilidade de adquirir Aids, através do uso de drogas injetáveis.

g) finalmente, alguns alunos das duas escolas acreditavam que a melhor forma de prevenção estava relacionada com a melhoria da inserção social do indivíduo.

\section{(...) Educação e emprego, né? Você dá emprego pra uma pessoa ela não precisa entrar no crime (Esc. Pub.)}

\section{(...) gente criada na rua, aprende, é muito mais fácil o acesso, né, você vê isso pe- los meninos de rua, que usam crack, usam, cheiram esmalte, cheiram cola, né, tudo pra suprir o nível de fome, isso tam- bém o governo podia ajudar dando (...) uma vida melhor, né, de ter condições (...)de comer (...) aí também diminui o uso de drogas (...) (Esc. Priv.)}

Dessa forma, foi possível identificar, nas propostas dos estudantes, a permanência bastante expressiva de componentes ideológicos da chamada "guerra às drogas" que no afã de combater qualquer tipo de uso, almejando uma sociedade idealizada, livre de drogas, adere a métodos de persuasão, controle e punição ${ }^{(2-3,28-29)}$. Novamente, a discussão acadêmica, que poderia dar elementos para que os estudantes tivessem melhores condições de avaliar a problemática do uso de drogas, parece estar obscurecida, prevalecendo noções distorcidas veiculadas
Conhecimento dos estudantes de enfermagem em relação às drogas psicotrópicas 
Fernanda Vieira de Campos Cássia Baldini Soares pelos órgãos de comunicação e, muitas vezes, estabelecidas pela impossibilidade de acesso a reflexões teóricas ou críticas que beneficiariam a compreensão das experiências conhecidas. Sabe-se que o enfoque repressivo que caracteriza os projetos de prevenção vem sendo cada vez mais criticado pelos estudos avaliativos ${ }^{(32)}$.

\section{Tema 4: Formação e atuação profissional: o viés da concepção biológica}

As principais disciplinas que abordaram o tema drogas psicotrópicas, segundo os alunos da escola privada, foram psiquiatria e, em segundo lugar, farmacologia. $\mathrm{Na}$ escola pública, essa relação se inverteu. É possível que isso tenha ocorrido porque, na escola privada, a disciplina de Psiquiatria havia sido ministrada durante o semestre imediatamente anterior ao da entrevista. Houve menção também de outras disciplinas, porém sem nenhum destaque especial. Trabalho de levantamento em 25 escolas de enfermagem de todo o país encontrou resultados semelhantes ${ }^{(19)}$. De fato, em se tratando de drogas, o enfoque puramente biológico, descontextualizado, desvinculado da totalidade vem sendo desenvolvido nas escolas desde o primeiro $\operatorname{grau}^{(33)}$.

Além do ensino formal de graduação, os entrevistados da escola privada consideraram que aprenderam mais sobre drogas a partir do meio social que freqüentavam e com amigos usuários. Em segundo lugar, mencionaram palestras no colégio. Já na escola pública, as fontes principais de aprendizado foram a mídia e o meio social, sendo as citações de aprendizado a partir da literatura e de atividades no colégio, como palestras, igualmente mencionadas.

Apenas uma pessoa da escola pública citou o uso pessoal como fonte de aprendizado. Também uma pessoa da escola privada considerou que sua experiência como dependente constituiu uma forma de aprendizado sobre as drogas.

A maioria dos alunos referiu sentir-se despreparada para atuar profissionalmente nessa área. No entanto, alguns estudantes da escola privada referiram um certo preparo devido a estágio específico em setor de álcool e drogas, possibilitado pela escola.
Apesar de considerarem-se despreparados para atuar profissionalmente nesse campo, os entrevistados alegaram que fazer prevenção "é mais fácil", desconectando o conhecimento da capacidade de intervenção na prevenção. Ou seja, para trabalhar em prevenção não é preciso ter conhecimento específico ou estar preparado.

Eu acho que é mais fácil trabalhar (...) na área de prevenção (...) eu me sinto mais preparado, talvez por achar mais fácil, pra trabalhar com a prevenção, do que com o tratamento (Esc. Priv.)

De prevenção sim, tratamento não. Porque na prevenção(...) eu acho um pouco mais light (...) (Esc. Pub.)

Alguns alunos da escola privada afirmaram estar preparados para trabalhar nas duas áreas, prevenção e tratamento. Outros sentiram-se aptos a atuar no tratamento. Apenas um aluno da escola pública relatou que trabalharia na área de tratamento. Um terço do total de alunos afirmaram que não trabalhariam em nenhum dos dois, ou por desinteresse na área, ou porque ainda não estavam preparados para essa atuação.

\section{CONCLUSÕES}

A caracterização da situação de aprendizado dos conteúdos sobre drogas psicotrópicas dos estudantes de enfermagem durante a graduação, em duas escolas, uma pública e uma privada, foi realizada através da apreensão de: conhecimento científico sobre drogas psicotrópicas e sua epidemiologia; motivações para o uso, regras sociais relacionadas ao uso de drogas e problemas decorrentes do uso; abordagens de intervenção social propostas pelos alunos; e formação e competência para atuação profissional na área.

Com relação ao conhecimento científico sobre drogas psicotrópicas, verificou-se que os alunos se apropriaram parcialmente de um conceito científico, prevalecendo uma redução conceitual que relaciona drogas aos psicofármacos. Isto se deve muito provavelmente ao fato de que os alunos estão recebendo esses conteúdos em disciplinas de psiquiatria e farmacologia.

Da mesma forma, os psicofármacos foram lembrados como importantes na epidemiologia do uso de drogas, bem como foram subestimadas as presenças das drogas lícitas: 
álcool e cigarro. Os usuários não apontaram distinções, exceto quando se atribuiu ao jovem o maior consumo. Assim, os estudantes desconheciam os levantamentos epidemiológicos, limitando-se a reforçar idéias de senso-comum transmitidas pela mídia.

As motivações para o uso de drogas, os problemas decorrentes do uso e as regras sociais apontadas revelaram a reprodução de mitos e preconceitos sobre drogas e usuários, especialmente presentes: na descrição de estereótipos que relacionam usuários a "criaturas menores"; no desconhecimento dos mecanismos pelos quais as drogas são proibidas ou liberadas; e na parcialidade dos discursos sobre drogas que enfocam seu lado negativo e fatalista.

A abordagem da guerra às drogas se manifestou de diversas formas nas propostas de intervenção social dos estudantes. Embora fizessem tentativas de pensar estratégias mais atinentes à abordagem da redução de danos, percebe-se uma nítida falta de subsídios nas propostas, pouco elaboradas e, muitas vezes, irrefletidas. É provável que os conteúdos ensinados nas disciplinas de psiquiatria e farmacologia - através das quais os alunos têm tido acesso a esse tipo de informação além da mídia e outros mecanismos de comunicação social, estejam ainda muito enfocados na repressão ao uso e ao usuário, resistindo à formulação de projetos de atuação que partem de uma compreensão histórico-social do uso de drogas, estimulando a tolerância e diminuindo o estigma sobre o usuário.

Como esperado, diante desse quadro, os estudantes referiram sentir-se despreparados e inseguros para atuação profissional. Paradoxalmente, acreditavam poder atuar na área de prevenção, parecendo considerar que esta tarefa poderia prescindir de conhecimentos científicos.

Essas considerações revelam a insuficiência do ensino de drogas na graduação em enfermagem e denunciam a adesão, ainda intensa, às tradições que alimentam o combate às drogas e vêm produzindo um contingente de usuários que não se encontram com possibilidade de acessar os serviços de saúde, devido à reprodução social de fórmulas que o caracterizam como doente ou criminoso.

Nossa tarefa é a de urgentemente readequar os conteúdos do ensino de drogas na enfermagem, uma vez que este profissional necessita ter uma base de conhecimento para orientar e planejar metas e ações nos espaços profissionais de atuação.

\section{REFERÊNCIAS}

(1) Bucher R. Drogas e drogadição no Brasil. Porto Alegre: Artes Médicas; 1992.

(2) Carlini-Cotrim BH. A escola e as drogas: realidade brasileira e contexto internacional. [tese] São Paulo (SP): Departamento de Psicologia Social da Pontifícia Universidade Católica de São Paulo; 1992.

(3) Soares CB. Adolescentes, drogas e AIDS: avaliando a prevenção e levantando necessidades. [tese] São Paulo (SP): Faculdade de Educação da USP; 1997.

(4) Almeida-Filho N, Santana V, Pinto I, Carvalho-Neto J. Is there an epidemic of drug misuse in Brazil? A review of the epidemiologic evidence (1977-1988). Int J Addict 1991;26(3): $355-65$.

(5) Carlini-Cotrim B. O consumo de substâncias psicotrópicas por estudantes secundários: o Brasil frente à situação internacional. Revista ABP-Apal 1991; 13(3): 112-6.
(6) Masur J, Carlini EA. Drogas: subsídios para uma discussão. $4^{\mathrm{a}}$ ed. São Paulo: Brasiliense; 1993.

(7) Galduróz JCF, Noto AR, Carlini, EA. IV Levantamento sobre o uso de drogas entre estudantes de $1^{\circ} \mathrm{e} 2^{\circ}$ graus em 10 capitais brasileiras: 1997. São Paulo: Centro Brasileiro de Informações sobre Drogas Psicotrópicas do Departamento de Psicobiologia da UNIFESP; 1997.

(8) Galduróz JCF, Noto AR, Nappo AS, Carlini, EA. I Levantamento domiciliar sobre o uso de drogas psicotrópicas 1999. São Paulo: Centro Brasileiro de Informações sobre Drogas Psicotrópicas do Departamento de Psicobiologia da UNIFESP; 2000.

(9) Andrade AG, Queiróz S, Villaboim RCM, Cesar CLG, Alves MCGP, Bassit AZ, et al. Uso de álcool e drogas entre alunos de graduação da Universidade de São Paulo (1996). Revista ABP-Apal 1997; 19(2): 53-9.
Conhecimento dos estudantes de enfermagem em relação às drogas psicotrópicas 
Fernanda Vieira de Campos Cássia Baldini Soares
(10) Andrade AG, Bassit AZ, Keer-Corrêa F, Tonhon AA, Boscovitz EP, Cabral M, et al. Fatores de risco associados ao uso se álcool e drogas na vida entre estudantes de medicina do Estado de São Paulo. Revista ABP-Apal 1997; 19(4): 117-26.

(11) Keer-Corrêa F, Andrade AG, Bassit AZ, Boccuto NMVF. Uso de álcool e drogas por estudantes de medicina da Unesp. Rev Bras Psiquiatr 1999; 21(2): 95-100.

(12) Luis MAV, Estevan SV. Inquérito sobre o uso de álcool e drogas numa população de estudantes universitários: Escola de Enfermagem de Ribeirão Preto. In: Anais da $48^{\text {a }}$ Reunião Anual da SBPC;1996 jul. 7-13; São Paulo. São Paulo: PUC-SP; 1996. v. 2, p. 106.

(13) Ministério da Educação e do Desporto. Diretrizes para uma política educacional de prevenção ao uso de drogas. Fórum de especialistas sobre a redução da demanda ao uso de drogas na América Latina. Brasília (DF); 1994.

(14) Velho G, editor. Individualismo e cultura. $5^{\mathrm{a}}$ ed. Rio de Janeiro: Zahar; 1999. Duas categorias de acusação na cultura brasileira contemporânea: individualismo e cultura; p. 55-64.

(15) Reale D. O caminho da redução de danos associados ao uso de drogas: do estigma à solidariedade. [dissertação] São Paulo (SP): Faculdade de Medicina da USP; 1997.

(16) Silva-Filho N. Pesquisa da UNESP aponta falhas nas campanhas de prevenção contra drogas [on-line] 2000. Disponível em: <http:/ /www.unesp.br/noticias/main10> (25 maio 2000).

(17) Soares CB, Faria LM. Prevenção de drogas no meio universitário: uma experiência na Universidade de São Paulo. Participação 2000; 4(6): 45-7.

(18) Kakuda AA, Luis MAV. O conteúdo sobre álcool e drogas ministrado aos alunos de enfermagem. In: Anais do $6^{\circ}$ Simpósio de Iniciação Científica da Universidade de São Paulo; 1998; Ribeirão Preto (SP). Ribeirão Preto: EERP; 1998. v. 1, p. 81, res. 6.25 .

(19) Ramos LH, Pillon SC, Cavalcante MBG, Luiz MV, Padredi F, Laranjeira RR. O ensino sobre dependência química em cursos de graduação em enfermagem no Brasil, 1998. Acta Paul Enferm 2001; 14(3):35-43.

(20) Bastos IF, Mesquita F, Marques LF. Troca de seringas: drogas e AIDS. Ciência, debate e saúde pública. Brasília(DF): Ministério da Saúde. Coordenação Nacional de DST e AIDS; 1998.
(21) Soares CB, Jacobi PR. Adolescentes, drogas e Aids: avaliação de um programa de prevenção escolar. Cad Pesqui 2000; (109): 213-37.

(22) O'Hare P. Redução de danos: alguns princípios e ação prática. In: Mesquita F, Bastos F, editores. Drogas e AIDS: estratégias de redução de danos. São Paulo: Hucitec; 1994.

(23) Marlatt GA. Redução de danos: estratégias práticas para lidar com comportamentos de alto risco. Porto Alegre: Artes Médicas; 1999.

(24) Bardin L. Análise de conteúdo. Trad. de Luís Antero Reto e Augusto Pinheiro. Lisboa: Edições 70; 1977.

(25) Ludke M, André M. Pesquisa em educação: abordagens qualitativas. São Paulo: EPU; 1986.

(26) Carlini-Cotrim B. Drogas: estranhando o óbvio. In: Abramo HW, Freitas MV, Sposito MP, editores. Juventude em debate. São Paulo: Cortez; 2000: p. 71-9.

(27) Bucher R. Drogas: o que é preciso saber para prevenir. $5^{\text {a }}$ ed. São Paulo:Fundo Social de Solidariedade do Estado de São Paulo; 1994.

(28) Bucher R, Oliveira S. O discurso do "combate às drogas" e suas ideologias. Rev Saúde Pública 1994; 28(2): 137-45.

(29) Ribeiro TW, Pergher NK, Torossian SD. Drogas e adolescência: uma análise da ideologia presente na mídia escrita destinada ao grande público. Psicol: Reflex Crít 1998; 11(3): 421-30.

(30) Coggiola O. O comércio de drogas hoje. Olho da História. [periódico online] 2001; (4). Disponível em: <http://www.ufba.br/ revistao/ 04coggio.html> (14 set. 2001).

(31) Carlini-Cotrim B, Rosemberg F. Os livros didáticos e o ensino para a saúde: o caso das drogas psicotrópicas. Rev Saúde Pública 1991; 25(4): 299-305.

(32) Noto AR, Galduróz JCF. O uso de drogas psicotrópicas e a prevenção no Brasil. Ciênc Saúde Coletiva 1999; 4(1): 145-51.

(33) Bueno SMV. Pesquisa-ação com delegados de ensino sobre sexualidade, DST, AIDS e drogas: um projeto pioneiro do interior do estado de São Paulo. J Bras Doenças Sex Transm 1997; 9(3):16-28. 